\title{
Anti-tumour necrosis factor alpha therapy improves insulin sensitivity in normal-weight but not in obese patients with rheumatoid arthritis
}

\author{
Antonios Stavropoulos-Kalinoglou ${ }^{1,2,3^{*}}$, Giorgos S Metsios ${ }^{3,4}$, Vasileios F Panoulas ${ }^{3}$, Peter Nightingale ${ }^{5}$,
} Yiannis Koutedakis ${ }^{1,2}$ and George D Kitas ${ }^{3,6}$

\begin{abstract}
Introduction: Insulin resistance (IR), a risk factor for the development of cardiovascular disease, is common among patients with rheumatoid arthritis (RA). Inflammation, and especially tumour necrosis factor alpha (TNF $\alpha$ ), has been associated with IR, and the administration of anti-TNF $\alpha$ agents is suggested to improve insulin sensitivity. However obesity, a potent contributor to IR, may limit the beneficial effects of anti-TNF $\alpha$ medication on IR. The aim of this study is to compare the effects of anti-TNF $\alpha$ therapy on IR between normal-weight and obese patients with RA.

Methods: Patients who were normal-weight with IR (N+IR) or obese with IR $(\mathrm{O}+\mathrm{IR})$ and had embarked on antiTNF $\alpha$ treatment, participated. Assessments included body mass index (BMI), insulin sensitivity (Homeostasis Model Assessment of insulin resistance, HOMA and the Quantitative Insulin sensitivity Check Index, QUICKI), and RA disease characteristics before and following six months of anti-TNF $\alpha$ treatment. Their results were compared to matched (for age, gender, BMI, disease duration and smoking status) normal-weight patients without IR (N-IR) and obese without IR (N-IR), respectively. In total, 32 patients were assessed for this study, with 8 in each group.

Results: Following six months of treatment, disease activity was significantly reduced in all groups $(P<0.05)$ to a similar extent ( $P$ for differences between groups $>0.05$ in all cases). In the total population, changes in HOMA (mean reduction at $6 \mathrm{~m}=-0.2 \pm 0.1 ; P=0.088$ ) and QUICKI (mean increase at $6 \mathrm{~m}=0.03 \pm 0.022 ; P=0.092$ ) after treatment were not statistically significant, though a trend towards improvement was observed. However, N+IR patients showed a significant decrease in HOMA (mean reduction at $6 \mathrm{~m}=-0.54 \pm 0.2 ; P=0.002$ ) and increase in QUICKI (mean increase at $6 \mathrm{~m}=0.046 \pm 0.02 ; P=0.011)$. These changes were significantly different compared to the other groups $(P<0.05$ in all cases). Multivariable analyses showed that the change in Erythrocyte Sedimentation Rate (ESR), and the change in C-Reactive Protein (CRP) associated with the improvement in HOMA (ESR: $F_{1-7}=5.143, P=0.019 ;$ CRP: $F_{1-7}=3.122$, $P=0.022$ ) and QUICKI (ESR: $F_{1-7}=3.814, P=0.021 ; C R P: F_{1-7}=2.67 ; P=0.041$ ) only in the N+IR group.
\end{abstract}

Conclusions: Anti-TNF $\alpha$ therapy, through controlling inflammation, seems to improve insulin sensitivity in normalweight RA patients with insulin resistance, but is not sufficient to achieving the same beneficial effect in obese RA patients with insulin resistance.

\section{Introduction}

Insulin resistance (IR), is a well established risk factor for the development of cardiovascular disease (CVD) [1]. The mechanisms of IR are under intense investigation; however, a consistent finding of such research is

\footnotetext{
* Correspondence: antonios.stav@gmail.com

'Department of Sport and Exercise Science, University of Thessaly, TrikalaKaryes Road, Trikala, 42100, Greece

Full list of author information is available at the end of the article
}

the close association between IR and inflammation [2-4]. Tumour necrosis factor alpha (TNF $\alpha$ ), a proinflammatory cytokine, is thought to be one of the main mediators of IR [2]. Patients with IR exhibit increased circulating levels of TNF $\alpha[5,6]$, and administration of TNF $\alpha$ induces IR in healthy individuals [7]. In otherwise healthy individuals, obesity is a significant contributor to IR; obesity is a low-grade inflammatory condition $[8,9]$

\section{(O) BioMed Central}


and TNF $\alpha$ is also thought to be the link between obesity and insulin resistance [3].

Rheumatoid arthritis (RA), associates with reduced life expectancy compared to the general population [10], mainly due to increased prevalence of CVD, and increased morbidity and mortality from CVD compared to the general population [11-13]. TNF $\alpha$ is central to the development and progression of RA and a common therapeutic target [14]. Apart from disease activity, treatment with anti-TNF $\alpha$ appears to also improve insulin sensitivity [15] and to reduce CVD risk in RA $[16,17]$. However, obesity a potent contributor to IR in the general population might influence the way anti-TNF $\alpha$ therapy affects IR. Indeed, in the general population, anti-TNF $\alpha$ does not improve IR in obese individuals [18]. The aim of this longitudinal study was to compare the effects of six months of anti-TNF $\alpha$ therapy on IR between normal weight and obese RA patients. Our primary hypothesis was that the possible beneficial effects of anti-TNF $\alpha$ on IR would be limited by the presence of obesity.

\section{Materials and methods Participants}

The study was conducted at the Dudley Group NHS Foundation Trust, UK. It had Research Ethics Committee approval by the Black Country Ethics Committee and local R\&D approval, and all volunteers provided written informed consent. Patients with RA, who were either normal weight with IR $(\mathrm{N}+\mathrm{IR})$ or obese with IR $(\mathrm{O}+\mathrm{IR})$ and embarked, for the first time, on clinically-indicated anti-TNF $\alpha$ treatment were invited to participate. Type of medication was decided by their managing physician and dosage was based on NICE guidelines. Patients with diabetes mellitus or using anti-diabetic medication were excluded from the study. The results of the $\mathrm{N}+\mathrm{IR}$ and $\mathrm{O}$ +IR patients were compared to age, gender, BMI, disease duration and smoking status matched normal-weight patients without IR (N-IR) and obese patients without IR (N-IR), respectively. A total of 32 patients were assessed; 8 in each of the groups: that is, N+IR, O+IR, N-IR and O-IR. Demographic and disease characteristics appear in Table 1.

\section{Assessments}

Standing height was measured to the nearest $0.5 \mathrm{~cm}$ on a Seca 214 Road Rod portable stadiometer (Seca gmbh \& co. kg., Hamburg, Germany). Body weight was assessed on a Tanita MA-418 BC body composition analyser (Tanita Corp., Tokyo, Japan). BMI $\left(\mathrm{kg} / \mathrm{m}^{2}\right)$ was calculated on the basis of measured height and weight. The recently published RA-specific BMI cut-off points (that is, $23 \mathrm{~kg} / \mathrm{m}^{2}$ for overweight and $28 \mathrm{~kg} / \mathrm{m}^{2}$ for obesity) were used to classify them as under-, normal-, overweight or obese [19].
Glucose and insulin were assessed in venous blood collected in the fasting state; IR was evaluated using the Homeostasis Model Assessment of insulin resistance (HOMA) [20] and the Quantitative Insulin sensitivity Check Index (QUICKI) [21], and was defined as HOMA $\geq 2.5$ [22] and/or QUICKI $\leq 0.333$ [23,24]. Both methods correlate well with insulin clamp (HOMA: $\mathrm{r}=0.88$ [22]; QUICKI: $r=0.78$ [21]) and are considered valid calculations for insulin resistance and insulin sensitivity, respectively. Smoking status was also recorded.

Inflammatory load was assessed by the erythrocyte sedimentation rate (ESR) and C-reactive protein (CRP). The Disease Activity Score-28 (DAS28) was used to assess clinical disease activity [25] and the anglicised version of the Stanford Health Assessment Questionnaire (HAQ) [26] to measure functional disability. Disease duration was recorded from review of the clinical notes. All assessments were repeated following six months of anti-TNF $\alpha$ therapy.

\section{Data management and analyses}

The Statistical Package for Social Sciences version 15.0 (SPSS Inc. Chicago, IL, USA) was used for the statistical analyses. The Kolmogorov-Smirnov test of normality was used to assess dispersion of the variables. Dispersion of data is reported as the mean (standard deviation-SD) as all were normally distributed. Statistical significance was set at $P<0.05$.

T-tests were used to identify differences at baseline in the assessed variables between N+IR and N-IR as well as $\mathrm{O}+\mathrm{IR}$ and $\mathrm{O}-\mathrm{IR}$. Repeated measures analysis of variance (ANOVA) was then used to evaluate the effects of sixmonth anti-TNF $\alpha$ treatment on HOMA and QUICKI as well as BMI, and RA characteristics, and identify differences between groups in the magnitude of these effects. Multivariate ANOVA (MANOVA) was then used to assess the associations between the changes in HOMA and QUICKI with baseline BMI, RA characteristics (ESR, CRP, DAS, HAQ), age and gender, as well as the change in these variables following treatment. Interactions between baseline BMI and age, disease duration and CRP were also included in the models.

\section{Results}

At baseline, t-tests did not identify any significant differences between the groups, other than, as expected, in IR (HOMA and QUICKI; Table 1). Following the six-month intervention, repeated measures ANOVA found no changes in BMI in any of the groups $(P>0.05)$. Inflammation and disease activity were significantly reduced in all groups $(P<0.05)$ but to a similar extent $(P$ for differences between groups $>0.05$ in all cases). Overall, HOMA showed a tendency to reduce $(P=0.088)$ while QUICKI a tendency to increase $(P=0.092)$ (Table 2). 
Table 1 Participant characteristics at baseline assessment

\begin{tabular}{|c|c|c|c|c|}
\hline & \multicolumn{2}{|c|}{ Normal Weight $(n=16)$} & \multicolumn{2}{|c|}{ Obese $(n=16)$} \\
\hline & + IR & $-I R$ & + IR & $-I R$ \\
\hline $\mathrm{N}$ (females) & $8(5)$ & $8(5)$ & $8(6)$ & $8(6)$ \\
\hline Anti-TNF $\alpha$ agent (Infliximab/Etanercept/Adalimumab) & $5 / 3 / 0$ & $4 / 3 / 1$ & $6 / 2 / 0$ & $5 / 3 / 0$ \\
\hline Smokers (current; ex) & $3(1 ; 2)$ & $4(1 ; 3)$ & $3(2 ; 1)$ & $4(2 ; 2)$ \\
\hline \multirow[t]{2}{*}{ Age (years) } & 60.8 & 62.2 & 58.6 & 60.8 \\
\hline & $(6.9)$ & $(7.8)$ & $(6.7)$ & $(8.0)$ \\
\hline \multirow[t]{2}{*}{ Height $(\mathrm{cm})$} & 165.9 & 167 & 165.4 & 165.2 \\
\hline & $(10.6)$ & $(12.2)$ & $(11.9)$ & $(9.4)$ \\
\hline \multirow[t]{2}{*}{ Weight (kg) } & 60.3 & 61.6 & 88.9 & 89.8 \\
\hline & $(6.4)$ & $(7.2)$ & $(10.1)$ & (9.6) \\
\hline \multirow[t]{2}{*}{ BMI $\left(\mathrm{kg} / \mathrm{m}^{2}\right)$} & 21.8 & 22.1 & 32.3 & 32.8 \\
\hline & $(2.4)$ & $(2.2)$ & $(3.0)$ & $(3.1)$ \\
\hline \multirow[t]{2}{*}{ HOMA } & 2.9 & $2.2^{*}$ & 3.1 & $2.1^{\#}$ \\
\hline & $(0.7)$ & $(0.4)$ & $(0.5)$ & $(0.8)$ \\
\hline \multirow[t]{2}{*}{ QUICKI } & 0.29 & $0.36^{*}$ & 0.30 & $0.37^{\#}$ \\
\hline & $(0.02)$ & $(0.03)$ & $(0.03)$ & $(0.01)$ \\
\hline \multirow[t]{2}{*}{ HAQ } & 1.6 & 1.8 & 1.7 & 2.0 \\
\hline & $(0.3)$ & $(0.2)$ & $(0.4)$ & $(0.5)$ \\
\hline \multirow[t]{2}{*}{ DAS } & 5.7 & 5.9 & 6.2 & 6.1 \\
\hline & $(0.7)$ & $(0.5)$ & $(1.0)$ & $(0.6)$ \\
\hline \multirow{2}{*}{ ESR $(\mathrm{mm} / \mathrm{h})$} & 31 & 38 & 35 & 43 \\
\hline & $(7.5)$ & (10) & $(9.5)$ & $(12.5)$ \\
\hline \multirow[t]{2}{*}{$\mathrm{CRP}(\mathrm{mg} / \mathrm{L})$} & 29 & 32.5 & 31.4 & 34.2 \\
\hline & $(6.4)$ & $(8.2)$ & $(8.8)$ & $(7.4)$ \\
\hline Disease Duration & 9.1 & 8.6 & 8 & 10.2 \\
\hline (years) & $(2.5)$ & $(2.3)$ & (3.6) & $(4.7)$ \\
\hline
\end{tabular}

* Significantly different compared to $\mathrm{N}+\mathrm{IR}(P<0.05)$. " Significantly different compared to O+IR $(P<0.05)$. BMI, body mass index; CRP, C-reactive protein; DAS disease activity score 28; ESR, erythrocyte sedimentation rate; $H A Q$, Health Assessment Questionnaire; +IR, with insulin resistance; $-I R$, without insulin resistance; HOMA, Homeostasis Model Assessment Of Insulin Resistance; QUICKI, Quantitative Insulin Sensitivity Check Index

When patient grouping was introduced as a factor in the analyses, it was revealed that the treatment resulted in significant decreases in $\operatorname{HOMA}(\Delta 6 \mathrm{~m}=-0.54 ; P=$ $0.002)$ and increases in QUICKI $(\Delta 6 \mathrm{~m}=0.046 ; P=$ 0.011 ) in the $\mathrm{N}+\mathrm{IR}$, but not any of the other three groups

Table 2 Effects of the treatment on the assessed variables for all participants

\begin{tabular}{ccc}
\hline & $\Delta 6 \mathrm{~m}$ & $\boldsymbol{P}$ \\
\hline BMI $\left(\mathrm{kg} / \mathrm{m}^{2}\right)$ & $0.45 \pm 0.07$ & 0.466 \\
DAS & $-2.37 \pm 0.4$ & 0.000 \\
HAQ & $-0.4 \pm 0.01$ & 0.001 \\
ESR $(\mathbf{m m} / \mathrm{h})$ & $-18.55 \pm 12.8$ & 0.002 \\
CRP $(\boldsymbol{\mu g} / \mathrm{L})$ & $-16.1 \pm 9.4$ & 0.016 \\
HOMA & $-0.2 \pm 0.1$ & 0.088 \\
QUICKI & $0.03 \pm 0.022$ & 0.092 \\
\hline
\end{tabular}

$\Delta 6 \mathrm{~m}$, mean difference between baseline and six-month measurement; BMI, body mass index; CRP, C-reactive protein; DAS, Disease Activity Score 28; ESR, erythrocyte sedimentation rate; $\mathrm{HAQ}$, Health Assessment Questionnaire; HOMA, Homeostasis Model Assessment Of Insulin Resistance; QUICKI, Quantitative Insulin Sensitivity Check Index.
( $P>0.05$ in all cases). The magnitude of the changes in IR was significantly different between $\mathrm{N}+\mathrm{IR}$ and the rest of the groups (N-IR: HOMA, $P=0.008$, QUICKI, $P=$ 0.002; O+IR: HOMA, $P=0.019$, QUICKI, $P=0.038$; OIR: HOMA, $P=0.000$, QUICKI, $P=0.001$; Figure 1$)$. No differences in the magnitude of improvements between the other groups were observed $(P>0.05$ for both HOMA and QUICKI).

Finally, MANOVA indicated that baseline BMI, baseline RA characteristics, baseline BMI, and the change in BMI did not associate with the change in HOMA or QUICKI in any of the groups $(P>0.05$ in all cases). However, the change in ESR and the change in CRP associated with the improvement in HOMA (ESR: $\mathrm{F}_{1-7}=5.143, P=0.019$; CRP: $\left.\mathrm{F}_{1-7}=3.122, P=0.022\right)$ and QUICKI (ESR: $\mathrm{F}_{1-7}=$ $3.814, P=0.021$; CRP: $\mathrm{F}_{1-7}=2.67 ; P=0.041$ ) only in the $\mathrm{N}+\mathrm{IR}$ group.

Retrospective power calculations $(\mathrm{a}=0.05)$ using the values observed above indicate a power of 0.91 and a power of 0.88 for the changes observed in HOMA $(\Delta 6$ $\mathrm{m}$ for $\mathrm{N}+\mathrm{IR}=0.49$, for $\mathrm{O}+\mathrm{IR}=0.11$, common St.D. $=$ 


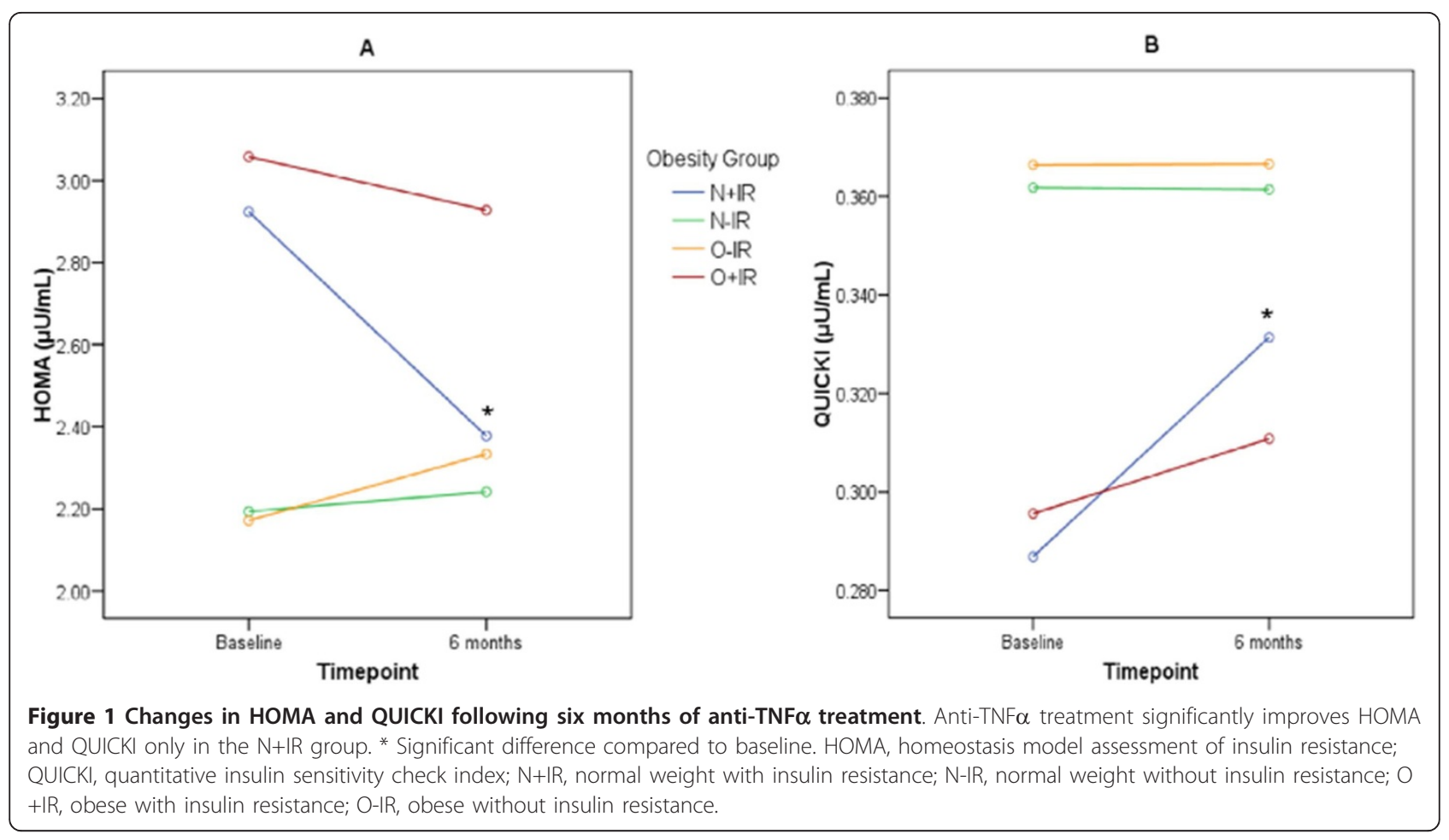

$0.26)$ and QUICKI $(\Delta 6 \mathrm{~m}$ for $\mathrm{N}+\mathrm{IR}=0.04$, for $\mathrm{O}+\mathrm{IR}=$ 0.01 , common St.D. $=0.02)$, respectively.

\section{Discussion}

The main aim of this study was to compare the effects of anti-TNF $\alpha$ treatment on insulin sensitivity among normal weight and obese RA patients. To our knowledge, this is the first study to use such an approach and indeed to identify different effects of anti-TNF $\alpha$ treatment in normal-weight vs. obese individuals with RA. Our results indicate a significant improvement of IR only in normal-weight RA patients with IR but not in obese RA patients with IR. Reduction in inflammation was associated with the changes in IR only in the normal weight but not in obese patients.

Sample size is the main limitation of our study. However, the number of patients that fulfilled the inclusion criteria for this study (that is, insulin resistance, antiTNF $\alpha$ naive and embarking on anti-TNF $\alpha$ ) is limited. This is also reflected by sample size of other studies investigating similar hypotheses [15]. In our study, a larger sample size might have been able to identify improvements in IR in the O+IR group. This group had a slight improvement in IR (as shown in Figure 1). However, this improvement was not statistically significant (mean change in HOMA: -0.11 ; $95 \%$ odds ratio: 0.06 to 0.15 ; and QUICKI: 0.009 ; $95 \%$ odds ratio: 0.004 to $0.018 ; P>0.05$ for both) or indeed clinically significant as both variables remained within the "at risk" range. Moreover, the statistical test we used (Repeated measures ANOVA) looks at the differences in the responses between the two groups, not merely the response of each group. We, therefore, doubt that a larger sample size would significantly change the conclusions of the present study. A second limitation of our study is that we did not control for changes in physical activity, which may influence IR. However, any such changes are likely to have occurred throughout all the subgroups, especially since disease activity was reduced equally among them. Additionally, for the duration of the study, no changes in thyroid status were observed (all patients were euthyroid at baseline), there were no changes in other anti-rheumatic medication (including steroids and hydroxychloroquine) or cardio/vasoactive therapy (including angiotensin-converting-enzyme (ACE) inhibitors).

Similar studies in RA patients have shown reduction in IR following anti-TNF $\alpha$ therapy (reviewed in [27]). BMI, even though assessed, is not reported in some of these studies [28,29]; in those who report it, observations are predominantly made on normal-weight to slightly overweight patients (BMI: approximately $22 \mathrm{~kg} / \mathrm{m}^{2}$ [30] to approximately $25 \mathrm{~kg} / \mathrm{m}^{2}$ [31,32]). Even in these studies increasing BMI appears to associate with a smaller improvement in IR [31]. Similarly, acute administration of anti-TNF $\alpha$ significantly improved insulin sensitivity in most RA patients; however, this improvement was again minimised with increasing BMI [33]. We have been able 
to find a single case-study of an obese patient with RA that experienced significantly improved IR following anti-TNF $\alpha$ treatment [34]; the extremely high baseline HOMA levels ( $>25$ with a cut-off for IR at 2.5) of this patient should be noted.

The reason for this apparent difference in the responses of lean vs. obese individuals to anti-TNF $\alpha$ is not yet clear. However, our findings for the obese RA patients are in line with data from the general population. In obese individuals with the metabolic syndrome [18] or with type 2 diabetes mellitus [35] anti-TNFa failed to improve IR. It is well established that enlarged adipose tissue is a source of inflammation. Up to $50 \%$ of its cell mass is monocytes and macrophages. Adipocytes and macrophages both are a source of inflammatory cytokines reducing insulin sensitivity of muscle and increasing plasma concentrations of these compounds $[36,37]$. The cytokines TNF $\alpha$ and interleukin-6 (IL-6) in particular, stimulate both the c-Jun amino-terminal kinase (JNK) and the I $\kappa$ B kinase- $\beta$ (IKK- $\beta$ )/nuclear factor $-\kappa \mathrm{B}(\mathrm{NF}-\kappa \mathrm{B})$ pathways, resulting in up-regulation of potential mediators of inflammation and lead to IR [38]. Other potential pathways by which obesity might induce IR include the action of retinol-binding protein-4 (RBP4) which reduces phosphatidylinositol-3-OH kinase $(\mathrm{PI}(3) \mathrm{K})$ signalling in muscle and enhances expression of the gluconeogenic enzyme phosphoenolpyruvate carboxykinase in the liver [39]. The role of IL-6 is of particular importance in the context of the present study, as this is not directly targeted by anti-TNF $\alpha$ medication and could thus be important in maintaining IR in obese individuals. A final interesting approach to the potential underlying mechanisms could be the role of the inflammasome and, especially, NLRP3 in IR. This is a cytosolic protein complex leading to the activation of the processing enzyme caspase- 1 , which is central to the production of Interleukin $-1 \beta$ (IL-1 $\beta$ ) [40]. IL-1 $\beta$ has been recently recognized as a potent instigator of the obesityinduced inflammation and as such a contributor to IR [41]. Even though anti-TNF $\alpha$ medication does not directly target IL-1 $\beta$, it is implicated in the activation of NLRP3 [42], thus indirectly affecting IL- $1 \beta$ production. The associations of obesity, inflammasomes and IL with IR in RA warrant further investigation.

Adipose tissue also secretes adipokines, such as adiponectin and resistin [43], reduced levels of adiponectin and increased levels of resistin associate with IR $[44,45]$. IR and other features of the metabolic syndrome independently associate with atherosclerosis in RA [46]. Adiponectin stimulates fatty acid oxidation via AMP-activated protein kinase (AMPK) and peroxisome proliferator activated receptor- $\alpha$-dependent pathways [38].
Anti-TNF $\alpha$ treatment may affect levels of these adipokines. In patients with severe RA, refractory to conventional disease-modifying antirheumatic drug (DMARD) therapy, periodical treatment with infliximab (an anti-TNFa blocker) results in a rapid reduction of serum resistin levels [47]. Serum resistin levels, in these patients, associate with laboratory markers of inflammation, particularly CRP, but not with BMI [47]. Moreover, in the same cohort of patients, an independent negative correlation of high-grade inflammation with circulating adiponectin concentrations has been observed [48]. Low adiponectin concentrations further correlate with atherogenic dyslipidemia and high plasma glucose [48].

Moreover, anti-TNF $\alpha$ treatment may reduce lipolysis within the muscle by inhibiting TNF $\alpha$ action locally [43] obese individuals have high fat intramuscular content. This may lead to further increases in intramuscular concentration of fatty acid metabolites, such as diacylglycerol, fatty acyl-coenzyme A, and ceramides, as a result of increased release of non-esterified fatty acids [39]. This leads to serine/threonine phosphorylation of insulin receptor substrate- 1 and -2 , and eventually to insulin resistance [49].

From a clinical point of view, our findings would suggest that additional measures to anti-TNFa therapy should be employed in order to combat IR in obese RA patients. Weight-loss is probably the primary such measure. However, due to the lack of weight-loss studies in RA [50] and the high prevalence of muscle wasting among these patients [51], any such interventions should be employed with great care. Exercise, which is known to benefit RA patients in several ways [52], could possibly prove a valuable tool in reducing body weight while maintaining muscle mass and improving insulin sensitivity, but further research is needed. In addition to IR, such interventions could improve other CVD risk factors and reduce the high CVD risk of RA patients.

From the above results, it seems that the effects of antiTNF $\alpha$ therapy on IR differ significantly between normalweight and obese patients with RA. Such therapy seems to improve IR in normal-weight but not in the obese RA patients. In the latter group, obesity-related processes seem to counteract the potential benefits of anti-TNF $\alpha$. Further studies looking at the specific mechanisms by which antiTNF $\alpha$ therapy affects IR and the mechanisms by which obesity interacts in this process should be pursued.

\section{Conclusions}

In conclusion, anti-TNF $\alpha$ therapy seems to improve insulin sensitivity in normal weight RA patients with IR but not in obese RA patients with IR. It is possible that the mechanisms leading to insulin resistance are partly different in normal-weight and obese patients with RA. 


\section{Abbreviations}

ACE inhibitor: angiotensin-converting-enzyme inhibitor; AMPK: AMP-activated protein kinase; ANOVA: analysis of variance; BMI: body mass index; CRP: Creactive protein; CVD: cardiovascular disease; DAS28: Disease Activity Score28; DMARD: disease-modifying antirheumatic drug; ESR: erythrocyte sedimentation rate; HAQ: Health Assessment Questionnaire; HOMA: Homeostasis Model Assessment of Insulin Resistance; IKK- $\beta$ : IKB kinase- $\beta$; IL-6: interleukin 6; IR: insulin resistance; +IR: normal-weight with insulin resistance; JNK: c-Jun amino-terminal kinase; MANOVA: multivariate analysis of variance; NF-KB: nuclear factor-KB; N-IR: normal-weight without insulin resistance; NO + IR: obese with insulin resistance; O-IR: obese without insulin resistance; PI(3) K: phosphatidylinositol-3-OH kinase; QUICKI: Quantitative Insulin sensitivity Check Index; RA: rheumatoid arthritis; RBP4: retinol-binding protein-4; TNFa: tumor necrosis factor alpha.

\section{Acknowledgements}

This study was funded by the Dudley Hospitals NHS Foundation Trust R\&D Directorate. The Department of Rheumatology, Dudley Hospitals NHS Foundation Trust, has an infrastructure support grant from Arthritis Research UK (number: 17682).

\section{Author details}

'Department of Sport and Exercise Science, University of Thessaly, TrikalaKaryes Road, Trikala, 42100, Greece. ${ }^{2}$ Institute of Human Performance and Rehabilitation, Centre for Research and Technology, Trikala, 42100, Greece. ${ }^{3}$ Department of Rheumatology, Dudley Group NHS Foundation Trust, Russell's Hall Hospital, Pensnett Road, Dudley, DY1 2HQ, West Midlands, UK. ${ }^{4}$ School of Sport, Performing Arts \& Leisure, Wolverhampton University, Gorway Road, Walsall, WS1 3BD, West Midlands, UK. ${ }^{5}$ Wolfson Laboratory, Department of Medical Statistics, School of Medicine, University of Birmingham, Queen Elizabeth Medical Centre, Edgbaston, Birmingham, B15 2TH, UK. ${ }^{6}$ Arthritis Research UK Epidemiology Unit, University of Manchester, Oxford Road, Manchester, M13 9PT, UK.

\section{Authors' contributions}

AS was involved in the conception and design of the study, and in data collection, data analyses and the writing of the manuscript. GM participated in the data collection and manuscript writing. VP was involved in data collection and data analyses. PN is the statistics expert of the team and led data analyses. YK was involved in the design of the study and drafting of the manuscript. GK was involved in the conception and design of the study, drafting of the manuscript, and acted as the study supervisor. All authors have read and approved the manuscript for publication.

\section{Competing interests}

The authors declare that they have no competing interests.

Received: 14 October 2011 Revised: 14 June 2012

Accepted: 5 July 2012 Published: 5 July 2012

\section{References}

1. McFarlane SI, Banerji M, Sowers JR: Insulin Resistance and Cardiovascular Disease. J Clin Endocrinol Metab 2001, 86:713-718.

2. Moller DE: Potential Role of TNF-[alpha] in the Pathogenesis of Insulin Resistance and Type 2 Diabetes. Trends in Endocrinology and Metabolism 2000, 11:212-217.

3. Dandona P, Aljada A, Bandyopadhyay A: Inflammation: the link between insulin resistance, obesity and diabetes. Trends in Immunology 2004, 25:4-7.

4. Shoelson SE, Lee J, Goldfine AB: Inflammation and insulin resistance. J Clin Invest 2006, 116:1793-1801.

5. Hotamisligil GS: Mechanisms of TNF-alpha-induced insulin resistance. Exp Clin Endocrinol Diabetes 1999, 107:119-125.

6. Saghizadeh M, Ong JM, Garvey WT, Henry RR, Kern PA: The expression of TNF alpha by human muscle. Relationship to insulin resistance. J Clin Invest 1996, 97:1111-1116.

7. Van der Poll T, Romijn JA, Endert E, Borm JJ, Buller HR, Sauerwein HP: Tumor necrosis factor mimics the metabolic response to acute infection in healthy humans. Am J Physiol 1991, 261:E457-465.

8. Ramos EJ, Xu Y, Romanova I, et al: Is obesity an inflammatory disease? Surgery 2003, 134:329-335.
9. Das UN: Is obesity an inflammatory condition? Nutrition 2001, 17:953-966.

10. Erhardt CC, Mumford PA, Venables PJ, Maini RN: Factors predicting a poor life prognosis in rheumatoid arthritis: an eight year prospective study. Ann Rheum Dis 1989, 48:7-13.

11. Kitas GD, Erb N: Tackling ischaemic heart disease in rheumatoid arthritis. Rheumatology (Oxford) 2003, 42:607-613.

12. Goodson N, Marks J, Lunt M, Symmons D: Cardiovascular admissions and mortality in an inception cohort of patients with rheumatoid arthritis with onset in the 1980s and 1990s 10.1136/ard.2004.034777. Annals of the Rheumatic Diseases 2005, 64:1595-1601.

13. Maradit-Kremers $\mathrm{H}$, Crowson CS, Nicola PJ, et al: Increased unrecognized coronary heart disease and sudden deaths in rheumatoid arthritis: A population-based cohort study. Arthritis \& Rheumatism 2005, 52:402-411.

14. Feldmann M: Development of anti-TNF therapy for rheumatoid arthritis. 2002, 2:364-371.

15. Gonzalez-Gay MA, Gonzalez-Juanatey C, Vazquez-Rodriguez TR, MirandaFilloy JA, Llorca J: Insulin resistance in rheumatoid arthritis: the impact of the anti-TNFá; therapy. Annals of the New York Academy of Sciences 2010, 1193:153-159.

16. Jacobsson LT, Turesson C, Gulfe A, et al: Treatment with tumor necrosis factor blockers is associated with a lower incidence of first cardiovascular events in patients with rheumatoid arthritis. J Rheumatol 2005, 32:1213-1218.

17. Jacobsson LT, Turesson C, Nilsson JA, et al: Treatment with TNF blockers and mortality risk in patients with rheumatoid arthritis. Ann Rheum Dis 2007, 66:670-675.

18. Bernstein LE, Berry J, Kim S, Canavan B, Grinspoon SK: Effects of etanercept in patients with the metabolic syndrome. Arch Intern Med 2006, 166:902-908.

19. Stavropoulos-Kalinoglou A, Metsios GS, Koutedakis Y, et al: Redefining overweight and obesity in rheumatoid arthritis patients. Ann Rheum Dis 2007, 66:1316-1321.

20. Radikova Z: Assessment of insulin sensitivity/resistance in epidemiological studies. Endocr Regul 2003, 37:189-194.

21. Katz A, Nambi SS, Mather K, et al: Quantitative Insulin Sensitivity Check Index: A Simple, Accurate Method for Assessing Insulin Sensitivity In Humans. J Clin Endocrinol Metab 2000, 85:2402-2410.

22. Matthews D, Hosker J, Rudenski A, Naylor B, Treacher D, Turner R: Homeostasis model assessment: insulin resistance and $\hat{I}^{2}$-cell function from fasting plasma glucose and insulin concentrations in man. In Book Homeostasis model assessment: insulin resistance and î2-cell function from fasting plasma glucose and insulin concentrations in man. Volume 28. City: Springer Berlin/Heidelberg; 1985:412-419, (Editor ed.^eds.).

23. Hrebícek J, Janout V, Malincíková J, Horáková D, Cízek L: Detection of Insulin Resistance by Simple Quantitative Insulin Sensitivity Check Index QUICKI for Epidemiological Assessment and Prevention 10.1210/ jc.87.1.144. Journal of Clinical Endocrinology \& Metabolism 2002, 87:144.

24. Ascaso JF, Pardo S, Real JT, Lorente RI, Priego A, Carmena R: Diagnosing Insulin Resistance by Simple Quantitative Methods in Subjects With Normal Glucose Metabolism 10.2337/diacare.26.12.3320. Diabetes Care 2003, 26:3320-3325.

25. Prevoo ML, van 't Hof MA, Kuper $H H$, van Leeuwen $M A$, van de Putte $L B$, van Riel PL: Modified disease activity scores that include twenty-eightjoint counts. Development and validation in a prospective longitudinal study of patients with rheumatoid arthritis. Arthritis Rheum 1995, 38:44-48.

26. Kirwan JR, Reeback JS: Stanford Health Assessment Questionnaire modified to assess disability in British patients with rheumatoid arthritis. Br J Rheumatol 1986, 25:206-209.

27. Gonzalez-Gay MA, Gonzalez-Juanatey C, Vazquez-Rodriguez TR, MirandaFilloy JA, Llorca J: Insulin resistance in rheumatoid arthritis: the impact of the anti-TNFa; therapy. Annals of the New York Academy of Sciences 2010, 1193:153-159.

28. Kiortsis DN, Mavridis AK, Vasakos S, Nikas SN, Drosos AA: Effects of infliximab treatment on insulin resistance in patients with rheumatoid arthritis and ankylosing spondylitis. Ann Rheum Dis 2005, 64:765-766.

29. Seriolo B, Paolino S, Ferrone C, Cutolo M: Effects of etanercept or infliximab treatment on lipid profile and insulin resistance in patients with refractory rheumatoid arthritis. Clin Rheumatol 2007, 26:1799-1800.

30. Tam LS, Tomlinson B, Chu TT, Li TK, Li EK: Impact of TNF inhibition on insulin resistance and lipids levels in patients with rheumatoid arthritis. Clin Rheumatol 2007, 26:1495-1498. 
31. Seriolo B, Ferrone C, Cutolo M: Longterm anti-tumor necrosis factor-alpha treatment in patients with refractory rheumatoid arthritis: relationship between insulin resistance and disease activity. The Journal of Rheumatology 2008, 35:355-357.

32. Huvers FC, Popa C, Netea MG, van den Hoogen FH, Tack CJ: Improved insulin sensitivity by anti-TNFalpha antibody treatment in patients with rheumatic diseases. Ann Rheum Dis 2007, 66:558-559.

33. Gonzalez-Gay MA, De Matias JM, Gonzalez-Juanatey C, et al: Anti-tumor necrosis factor-alpha blockade improves insulin resistance in patients with rheumatoid arthritis. Clin Exp Rheumatol 2006, 24:83-86.

34. Yazdani-Biuki B, Stelzl H, Brezinschek HP, et al: Improvement of insulin sensitivity in insulin resistant subjects during prolonged treatment with the anti-TNF-alpha antibody infliximab. Eur J Clin Invest 2004, 34:641-642.

35. Ofei F, Hurel S, Newkirk J, Sopwith M, Taylor R: Effects of an engineered human anti-TNF-alpha antibody (CDP571) on insulin sensitivity and glycemic control in patients with NIDDM. Diabetes 1996, 45:881-885.

36. Andersson CX, Gustafson B, Hammarstedt A, Hedjazifar S, Smith U: Inflamed adipose tissue, insulin resistance and vascular injury. Diabetes Metab Res Rev 2008, 24:595-603.

37. Berg $\mathrm{AH}$, Scherer PE: Adipose tissue, inflammation, and cardiovascular disease. Circ Res 2005, 96:939-949.

38. Kahn SE, Hull RL, Utzschneider KM: Mechanisms linking obesity to insulin resistance and type 2 diabetes. 2006, 444:840-846.

39. Yang $Q$, Graham TE, Mody N, et al: Serum retinol binding protein 4 contributes to insulin resistance in obesity and type 2 diabetes. 2005, 436:356-362.

40. Stienstra R, Tack Cees J, Kanneganti T-D, Joosten Leo AB, Netea Mihai G The Inflammasome Puts Obesity in the Danger Zone. Cell metabolism 2012, 15:10-18.

41. Horng T, Hotamisligil GS: Linking the inflammasome to obesity-related disease. Nat Med 2011, 17:164-165.

42. Franchi L, Eigenbrod T, Núñez G: Cutting Edge: TNF-a Mediates Sensitization to ATP and Silica via the NLRP3 Inflammasome in the Absence of Microbial Stimulation. The Journal of Immunology 2009, 183:792-796.

43. Lo J, Bernstein LE, Canavan B, et al: Effects of TNF-alpha neutralization on adipocytokines and skeletal muscle adiposity in the metabolic syndrome. Am J Physiol Endocrinol Metab 2007, 293:E102-109.

44. Ziemke F, Mantzoros CS: Adiponectin in insulin resistance: lessons from translational research. Am J Clin Nutr 2010, 91:258S-261.

45. Steppan CM, Lazar MA: Resistin and obesity-associated insulin resistance. Trends in Endocrinology and Metabolism 2002, 13:18-23.

46. Gonzalez-Gay MA, Gonzalez-Juanatey C, Miranda-Filloy JA, Garcia-Porrua C, Llorca J, Martin J: Cardiovascular disease in rheumatoid arthritis. Biomedecine \& Pharmacotherapy 2006, 60:673-677.

47. Gonzalez-Gay MA, Garcia-Unzueta MT, Gonzalez-Juanatey C, et al: Anti-TNFalpha therapy modulates resistin in patients with rheumatoid arthritis. Clinical and experimental rheumatology 2008, 26:311-316.

48. Gonzalez-Gay MA, Llorca J, Garcia-Unzueta MT, et al: High-grade inflammation, circulating adiponectin concentrations and cardiovascular risk factors in severe rheumatoid arthritis. Clinical and experimental rheumatology 2008, 26:596-603.

49. Shulman Gl: Cellular mechanisms of insulin resistance. The Journal of Clinical Investigation 2000, 106:171-176.

50. Stavropoulos-Kalinoglou A, Metsios GS, Koutedakis Y, Kitas GD: Obesity in rheumatoid arthritis. Rheumatology (Oxford) 2011, 50:450-462.

51. Summers GD, Metsios GS, Stavropoulos-Kalinoglou A, Kitas GD: Rheumatoid cachexia and cardiovascular disease. Nature reviews Rheumatology 2010, 6:445-451.

52. Metsios GS, Stavropoulos-Kalinoglou A, Veldhuijzen van Zanten JJ, et al: Rheumatoid arthritis, cardiovascular disease and physical exercise: a systematic review. Rheumatology (Oxford) 2008, 47:239-248.

\section{doi:10.1186/ar3900}

Cite this article as: Stavropoulos-Kalinoglou et al: Anti-tumour necrosis factor alpha therapy improves insulin sensitivity in normal-weight but not in obese patients with rheumatoid arthritis. Arthritis Research \& Therapy 2012 14:R160.

\section{Submit your next manuscript to BioMed Central and take full advantage of:}

- Convenient online submission

- Thorough peer review

- No space constraints or color figure charges

- Immediate publication on acceptance

- Inclusion in PubMed, CAS, Scopus and Google Scholar

- Research which is freely available for redistribution 